\title{
The effects of sympathetic nervous system activation and psychological stress on glucose metabolism and blood pressure in subjects with Type 2 (non-insulin-dependent) diabetes mellitus
}

\author{
D. G. Bruce, D. J. Chisholm, L. H. Storlien, E.W. Kraegen and G. A.Smythe \\ Garvan Institute of Medical Research, St. Vincent's Hospital, Sydney, Australia
}

Summary. The sympathetic nervous system may contribute to excessive hepatic glucose output in Type 2 (non-insulin dependent) diabetes mellitus and could be implicated in the interrelated problem of hypertension. The aim of these studies was to determine whether subjects with Type 2 diabetes had normal sensitivity (compared with age- and weight-matched non-diabetic subjects) to noradrenaline infusion ( $60 \mathrm{ng}$. $\mathrm{kg}^{-1} \cdot \mathrm{min}^{-1}$ for $\left.60 \mathrm{~min}\right)$ and to compare the responses with oral tyramine administration $(800 \mathrm{mg})$, and psychological stress (using competitive computer games). Noradrenaline infusion caused significantly greater plasma glucose (mean increment $2.1 \pm 0.4$ vs $0.6 \pm 0.1 \mathrm{mmol} / 1, p<0.005$ ) and pressor responses (mean systolic increment $21 \pm 3$ vs $11 \pm 1 \mathrm{mmHg}, p<0.02)$ in the diabetic subjects. The excessive glycaemia was due to increased hepatic glucose output rather than reduced glucose disposal. Tyramine administration caused significantly increased hepatic glucose output and plasma glucose levels, but with similar responses in the diabetic and non-diabetic subjects; the pulse and pressor responses were also similar between the groups. The psychological stressor induced significant increases in pulse, blood pressure and non-esterified fatty acid levels in the combined group of subjects $(p<0.01)$ but did not influence plasma glucose levels in either diabetic or non-diabetic subjects. We conclude that pharmacologically-induced sympathetic nervous stimulation can induce hyperglycaemia. Subjects with uncomplicated Type 2 diabetes have increased sensitivity to exogenous noradrenaline but may not hyperrespond to endogenous sympathetic activation.

Key words: Type 2 (non-insulin-dependent) diabetes mellitus, sympathetic nervous system, noradrenaline, tyramine, blood pressure.
Increased liver glucose production is a major determinant of hyperglycaemia in Type 2 (non-insulin-dependent) diabetes mellitus. The cause of excessive hepatic glucose production is unknown but could involve hormones, neuroendocrine factors, gluconeogenic substrate supply and impaired glucose autoregulation. The sympathetic nervous system may modulate hepatic glucose output [1-3] and hepatic nerve stimulation has increased plasma glucose levels in humans [4]. Sympathetic activation may also affect hepatic glucose output via changes in insulin, glucagon and catecholamine levels.

Type 2 diabetes may be characterised by increased basal sympathetic tone. Alpha-adrenergic receptor blockade increases basal and stimulated insulin levels in Type 2 diabetes more than in non-diabetic subjects $[5,6]$ and the alpha-2 adrenergic receptor blocking agent Midaglizole (DG5128) improves glucose tolerance [7]. Alternatively, increased sensitivity to sympathetic nervous stimulation may be induced in Type 2 diabetes during stress [8]; relaxation therapy has improved glucose tolerance in subjects with Type 2, but not Type 1 (insulin-dependent) diabetes $[9,10]$. Induced psychological stress does not alter glycaemia in Type 1 diabetes [11] but has not been examined in Type 2 diabetes. High blood pressure is associated with both Type 2 diabetes and insulin resistance $[12,13]$.

The present studies aimed to determine whether subjects with Type 2 diabetes had increased sensitivity to direct noradrenergic stimulation, to pharmacological activation of the sympathetic nervous system (oral tyramine) and to psychological stress.

\section{Subjects and methods}

Eight male subjects with Type 2 diabetes (duration 0.5-18, mean 5.1 years) and six male non-diabetic subjects were selected based on the following criteria: absence of treatment for hypertension, no clinical autonomic neuropathy (heart rate interval variation was tested [14] in diabetic subjects), no contraindication to receiving adrenergic agents, normal serum creatinine levels and absence of proteinuria. The diabetic and non-diabetic groups were well 
Table 1. Mean baseline data for the diabetic and non-diabetic subjects. Values are the mean of basal values before each study condition (i. e. two or four studies)

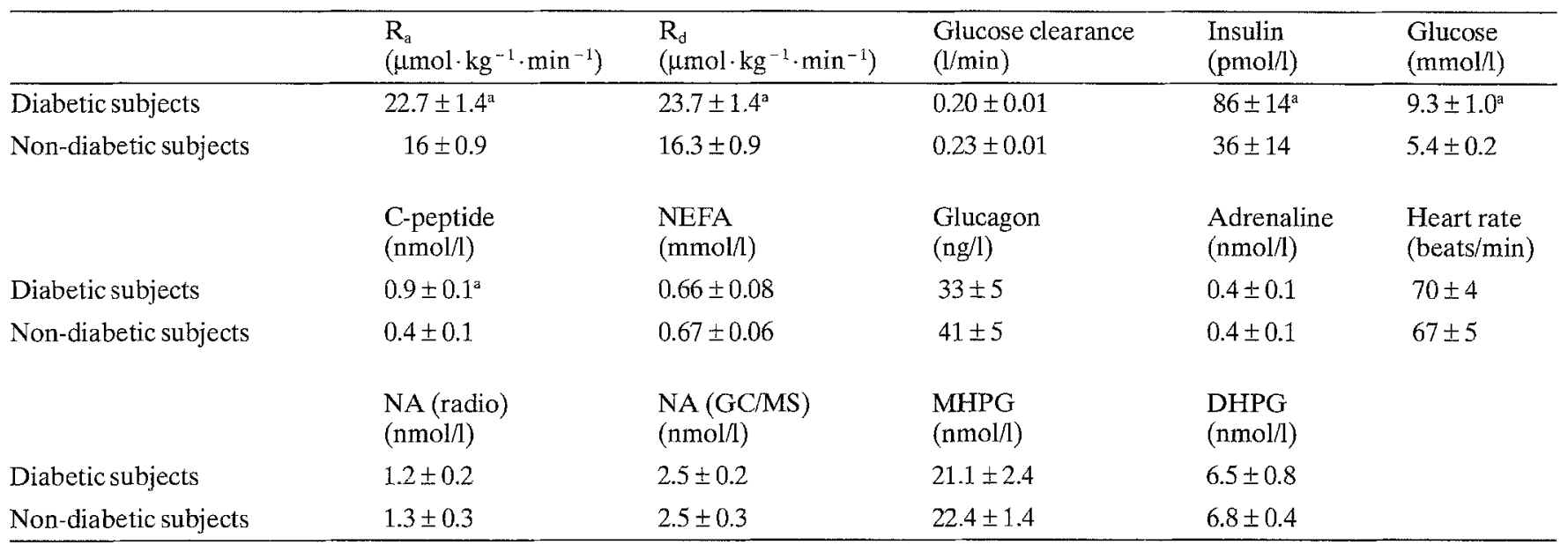

a indicates significant difference between groups

$\mathrm{R}_{\mathrm{a}}$, Glucose appearance; $\mathrm{R}_{\mathrm{d}}$, glucose disappearance; GC/MS, gas chromatography/mass spectroscopy; MHPG, methoxyhydroxyphe-

matched for age $(56.5 \pm 2.4$ vs $50.5 \pm 4.2$ years, mean $\pm S E M)$ and blood pressure (systolic $120 \pm 6$ vs $119 \pm 5$, diastolic $79 \pm 4$ vs $78 \pm 2 \mathrm{~mm} \mathrm{Hg}$ ) though two diabetic subjects had mildly elevated diastolic pressures $(138 / 99$ and $132 / 96 \mathrm{~mm} \mathrm{Hg}$ ) while body mass index differed by less than $12 \%\left(27.2 \pm 0.9 \mathrm{vs} 24.1 \pm 0.5 \mathrm{~kg} / \mathrm{m}^{2}\right)$; all but one diabetic subject were within $15 \%$ of ideal body weight. Three subjects were treated with sulphonylureas (glibenclamide or gliclazide), the rest with diet alone. Two diabetic subjects had an asymptomatic sensory peripheral neuropathy and two had a heart rate interval variation more than one SD less than age-matched control subjects [14]. One non-diabetic subject was euthyroid and being treated with thyroxine for hypothyroidism. Informed consent was obtained from all subjects prior to the study, which was approved by the St. Vincents Hospital Research Ethics Committee and was performed in accordance with the principles of the Declaration of Helsinki.

Studies were performed in random order, at intervals of at least 2 weeks, on the morning after an overnight fast. The subjects were in the sitting position with sulphonylurea therapy having ceased $48 \mathrm{~h}$ beforehand. Fasting blood glucose in the diabetic subjects was $9.3 \pm 1.0 \mathrm{mmol} / 1$. All subjects participated in all studies, except one diabetic subject who suffered a vaso-vagal attack following his first study (psychological stress) and returned only for a control study.

Catheters were inserted into an antecubital vein for $\left[3-{ }^{3} \mathrm{H}\right] \mathrm{glu}-$ cose infusion and an ipsilateral dorsal hand vein, with the hand kept warm in a heating pad, for arterialised venous blood sampling [15]. An additional contralateral venous catheter was inserted for noradrenaline infusion. A 90 -min period was allowed for equilibration of the $\left[3{ }^{3} \mathrm{H}\right]$ glucose infusion prior to any intervention [16]. Blood pressure (mercury sphygmomanometer) and pulse rate (continuous ECG monitor) were measured throughout. Blood was drawn for plasma glucose and $\left[3-{ }^{3} \mathrm{H}\right] \mathrm{glucose}$ specific activity at $5-10 \mathrm{~min}$ intervals and for serum insulin, C-peptide, non-esterified fatty acid (NEFA), adrenaline, noradrenaline, noradrenaline metabolites, cortisol and plasma glucagon at $15-30 \mathrm{~min}$ intervals.

Noradrenaline hydrochloride solution was dissolved in $0.9 \%$ $\mathrm{NaCl}$ with $0.05 \%$ ascorbic acid to give a concentration of $8 \mu \mathrm{g} / \mathrm{ml}$ and was protected from light; noradrenaline was infused at $60 \mathrm{ng} \cdot \mathrm{min}^{-1} \cdot \mathrm{kg}^{-1}$ for $60 \mathrm{~min}$ to elevate circulating noradrenaline levels well above the physiological range in order to achieve an increase in concentration at noradrenaline receptors approximating a physiological stimulus, i.e. a $10-25 \mathrm{~mm} \mathrm{Hg}$ rise in systolic blood pressure (see Results). Tyramine hydrochloride, $4 \times 200 \mathrm{mg}$ capsules, was administered orally.

Psychological stress was achieved by requiring challenging competitive computer games to be performed; this induces moderate psy- nylethyleneglycol; DHPG, dihydroxyphenylethyleneglycol; NA, noradrenaline; radio, radioenzymatic measurement

chological tension and alterations in blood pressure and pulse in nondiabetic individuals [17]. Subjects were seated in front of a personal computer (Apple IIe, Apple Computer Inc. Cupertino, Calif., USA) and asked to perform a series of unspecified psychological tests, and were told that the results would be compared with other subjects. After the 90-min equilibration period, they played a series of computer games for $60 \mathrm{~min}$, being given a (difficult to achieve) target score, said to be the average obtained by previous subjects, to be reached within $20 \mathrm{~min}$. They were given a new task after $20 \mathrm{~min}$ or if they reached the target. Their performance was critically evaluated at intervals to encourage greater effort. Prior to this study, the subjects completed the State-Trait Anxiety Inventory [18] which measures both chronic (trait) and acute (state) anxiety levels. The 'state'section was completed again after the study to assess the level of anxiety induced [18]. The control study involved quiet reading and relaxation.

\section{Hormone and substrate measurements}

Plasma glucose, serum insulin, C peptide, NEFA, cortisol and plasma glucagon were measured as previously described [16, 19]. Plasma catecholamines were measured using two methods. Plasma noradrenaline and adrenaline levels were measured using a radioenzymatic assay (CAT-A-KIT, Amersham Int., Amersham, Bucks., UK). The intra- and inter-assay coefficients of variation are $4.2 \%$ and $7.5 \%$ for noradrenaline and $3.6 \%$ and $10 \%$ for adrenaline. Plasma free levels of noradrenaline and its metabolite, dihydroxyphenylethylene glycol (DHPG), were also measured at baseline and at 60 min after commencement of each study using a specific and precise gas chromatograph/mass spectrometry (GC/MS) assay with deuterated internal standards [20]. Differences were noted for the two methods in absolute noradrenaline levels but relative changes were similar. Plasma free methoxyhydroxyphenylethylene glycol (MHPG), another metabolite of noradrenaline, and tyramine levels were also determined using GC/MS [21]. Tyramine levels were estimated semi-quantitatively by reference to the internal deuterated MHPG standard and expressed in arbitrary units per $\mathrm{ml}$.

\section{Statistical analysis}

Glucose turnover in the non-steady state was determined as described previously using a pool-fraction model of the glucose space assuming a rapidly mixing glucose pool equivalent to $17 \%$ of body 

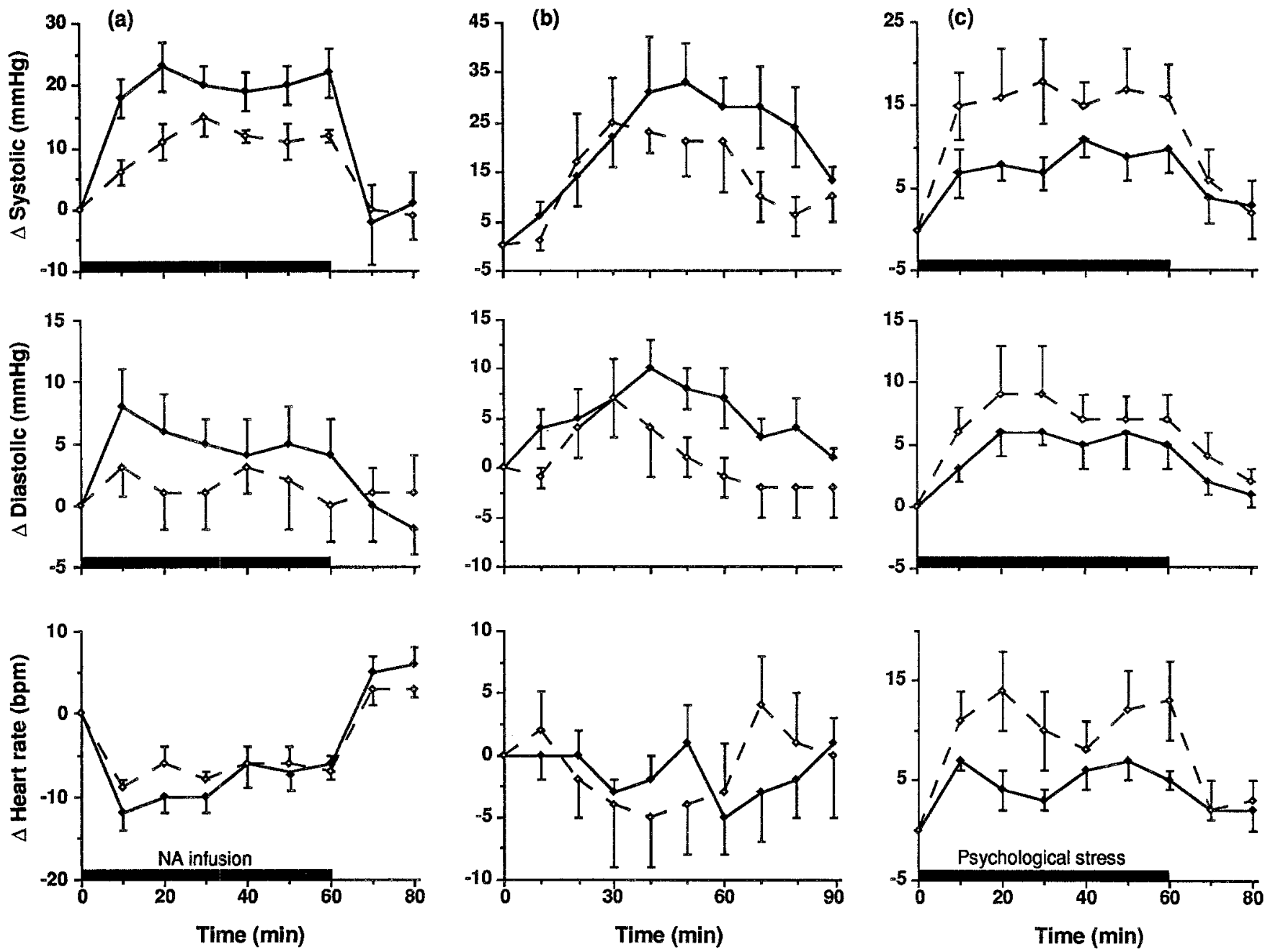

Fig. 1. Mean ( \pm SEM) incremental systolic, diastolic pressor and heart rate responses to (a) noradrenaline (NA) infusion (from $0-60 \mathrm{~min}$ ), (b) oral tyramine administration and (c) psychological

stress, in the diabetic (closed symbols, solid line) and non-diabetic subjects (open symbols, broken line)

weight [16]. Information published since the performance of this study [22] indicates that, especially in subjects with reduced glucose clearance and a large pool size, steady-state tracer specific activity may be underestimated and systemic glucose appearance overestimated. Qualitative responses within groups can be interpreted with confidence but quantitative comparisons between groups are only made with comparative changes in glycaemia. Hormone, substrate and turnover data were evaluated as absolute responses and incremental responses above baseline. Where any parameter altered during the control studies, total and incremental (relative to control) responses were assessed. Total incremental responses were compared between diabetic and non-diabetic groups by unpaired Student's $t$-test. Paired $t$-tests were used when appropriate. Other statistical comparisons used simple regression analysis. All significant differences in blood pressure or blood glucose responses were additionally assessed by the non-parametric Wilcoxon and Mann-Whitney tests, in each case confirming the significance.

\section{Results}

\section{Baseline values (Table 1)}

Mean basal concentrations (mean for all studies) of plasma glucose $(p<0.01)$, insulin $(p<0.02)$ and $C$ peptide $(p<0.02)$ and basal hepatic glucose output $(p<0.005)$ and peripheral glucose disposal $(p<0.005)$ were significantly increased in diabetic vs non-diabetic subjects (recognising the limitations in the last two comparisons); there was no difference in basal levels of NEFA, noradrenaline, MHPG, DHPG, adrenaline, glucagon and cortisol. There was no difference in basal values for any parameter before each of the four studies in either group nor was there any change in any parameter during the control study except for plasma glucose levels which fell in the diabetic subjects only.

Noradrenaline infusion resulted in similar increases in arterial noradrenaline levels in both subject groups, whether measured by GC/MS or radioenzymatic methods; there was a disparity in levels measured by the two assays though the relative change was similar (diabetic vs nondiabetic: GC/MS assay, basal $2.7 \pm 0.4$ vs $2.3 \pm 0.2,60 \mathrm{~min}$ $14.1 \pm 1.5 \mathrm{vs} 12.9 \pm 1.0 \mathrm{nmol} / \mathrm{l}$; radioenzymatic assay basal $1.5 \pm 0.4$ vs $1.4 \pm 0.6,60 \mathrm{~min} 5.7 \pm 2.0$ vs $4.5 \pm 2.4 \mathrm{nmol} / 1)$. Adrenaline $(0.4 \pm 0.1 \mathrm{nmol} / \mathrm{l})$ and DHPG levels did not alter during noradrenaline infusion. In all subjects who had MHPG levels determined at $30 \mathrm{~min}$ after noradrenaline infusion, there was a considerable increase in 


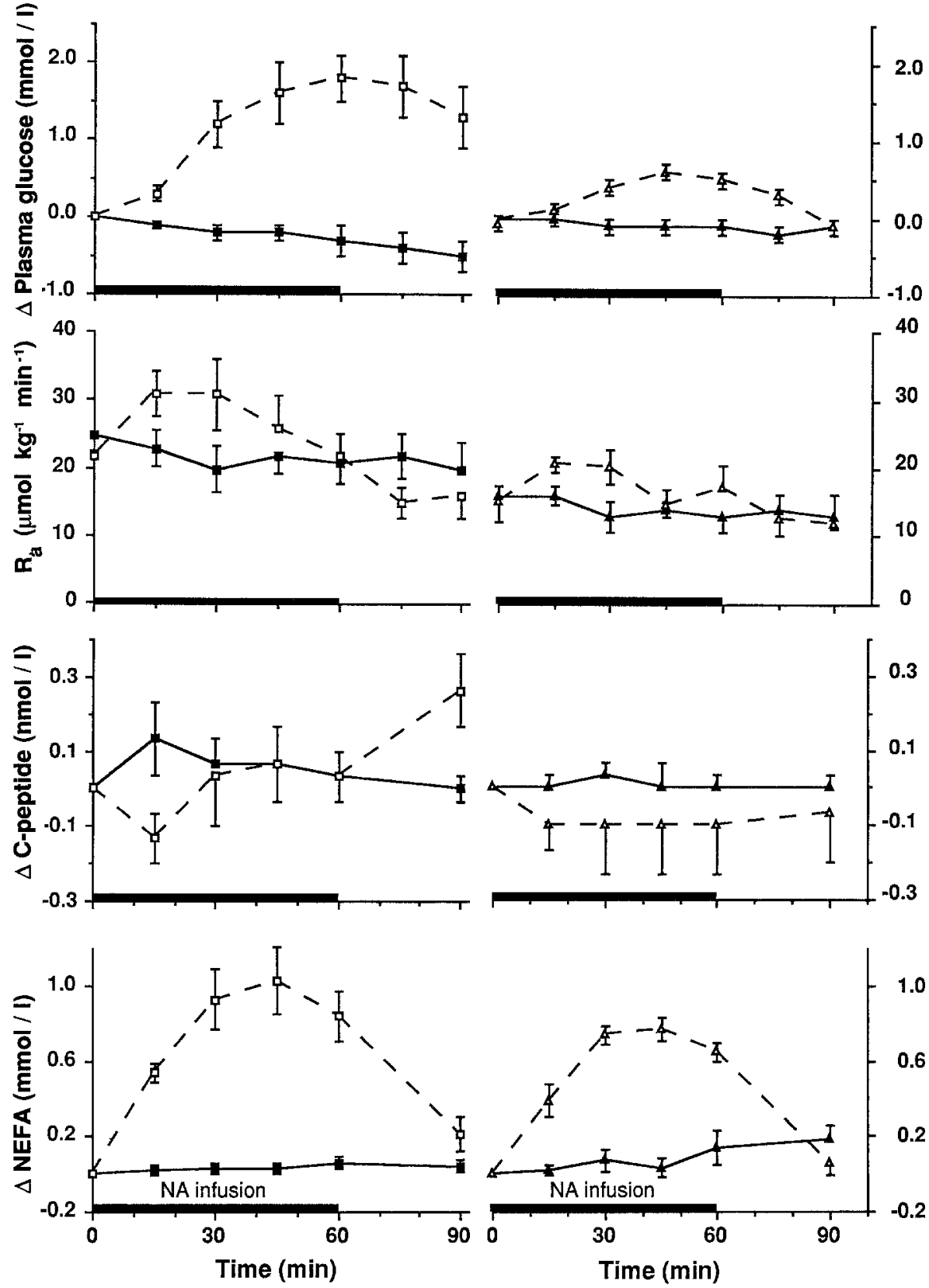

0 0 0 . 
Table 2. Mean ( \pm SEM) catecholamine, hormone and tyramine levels (arbitrary units) at baseline, 30 and 60 min after oral tyramine administration

\begin{tabular}{|c|c|c|c|c|c|c|}
\hline & \multicolumn{3}{|c|}{ Diabetic subjects } & \multicolumn{3}{|c|}{ Non-diabetic subjects } \\
\hline & Basal & 30 & 60 & Basal & 30 & 60 \\
\hline $\mathrm{NA}(\mathrm{GC} / \mathrm{MS})(\mathrm{nmol} / \mathrm{l})$ & $2.4 \pm 0.2$ & - & $3.3 \pm 0.3^{2}$ & $2.4 \pm 0.4$ & - & $4.6 \pm 0.8^{a}$ \\
\hline MHPG (nmol/l) & $23.4 \pm 4.0$ & $26.0 \pm 4.8$ & $34.0 \pm 6.8^{\mathrm{a}}$ & $30.8 \pm 4.8$ & $36.4 \pm 5.4$ & $45.9 \pm 5.4^{\mathrm{a}}$ \\
\hline DHPG (nmol/l) & $7.0 \pm 0.6$ & - & $15.3 \pm 1.3^{\mathrm{a}}$ & $6.1 \pm 1.1$ & - & $13.7 \pm 2.6^{\mathrm{a}}$ \\
\hline Tyramine (units ${ }^{\mathrm{b}}$ ) & 0 & $645 \pm 352^{a}$ & $1476 \pm 444^{\mathrm{a}}$ & 0 & $598 \pm 46^{\text {a }}$ & $840 \pm 474^{a}$ \\
\hline Adrenaline (nmoll) & $0.5 \pm 0.1$ & $0.4 \pm 0.2$ & $0.5 \pm 0.2$ & $0.4 \pm 0.2$ & $0.4 \pm 0.2$ & $0.5 \pm 0.3$ \\
\hline Glucagon (ng/l) & $32 \pm 9$ & $44 \pm 13$ & $30 \pm 11$ & $26 \pm 9$ & $68 \pm 27$ & $37 \pm 12$ \\
\hline $\operatorname{NEFA}(\mathrm{mmol} / \mathrm{l})$ & $0.65 \pm 0.09$ & $0.82 \pm 0.13^{a}$ & $0.83 \pm 0.12$ & $0.77 \pm 0.1$ & $0.85 \pm 0.14$ & $0.85 \pm 0.12$ \\
\hline
\end{tabular}

${ }^{a} p<0.05$ compared with basal levels.

$\mathrm{b}$ arbitrary units (see Methods)

NA, Noradrenaline; GC/MS, gas chromatography/mass spectros-

copy; MHPG, methoxyhydroxyphenylethyleneglycol; DHPG, dihydroxyphenylethyleneglycol; radio, radioenzymatic measurement

both groups $(p<0.1)$ and integrated responses were not significantly greater in the diabetic subjects $(1862 \pm 770 \mathrm{vs}$ $743 \pm 326 \mathrm{ng} /(1.60 \mathrm{~min}))$. There were significant similar increases in plasma NEFA levels $(p<0.01)$ in the two groups (Fig.2, integrated responses above control, $42.60 \pm 5.85$ vs $31.23 \pm 2.73 \mathrm{mmol} /(1.60 \mathrm{~min}))$.

Correlations. There was a significant $(r=0.65, p<0.02)$ correlation between glycaemic and systolic pressor responses during noradrenaline infusion.

Oral tyramine administration (Table 2) resulted in significant $(p<0.05)$ increases in circulating levels of tyramine, noradrenaline, MHPG and DHPG, which were similar in both subject groups. Adrenaline levels did not change. Tyramine caused a similar increase in systolic blood pressure in both groups (Fig. 1, diabetic vs non-diabetic: peak systolic increment, $49 \pm 8$ vs $40 \pm 7 \mathrm{~mm} \mathrm{Hg}$; integrated increment, $1926 \pm 321$ vs $1293 \pm 254 \mathrm{~mm} \mathrm{Hg} / 90 \mathrm{~min}$ ). There was no significant difference in the diastolic pressor and heart rate responses.

Plasma glucose levels rose significantly in both groups $(p<0.025$, Fig. 3$)$ with no significant group difference (integrated responses above control: diabetic, $33.7 \pm 10.9$ vs $20.5 \pm 6.3 \mathrm{mmol} /(1.90 \mathrm{~min}))$. $\mathrm{R}_{\mathrm{a}}$ was not significantly increased in the diabetic $(0.05<p<0.1)$ or non-diabetic subjects (integrated increment above control, $347.1 \pm 148.6$ and $111.4 \pm 288.6 \mu \mathrm{mol} \cdot\left(\mathrm{kg}^{-1} \cdot 90 \mathrm{~min}^{-1}\right)$. When the data for all subjects were combined, there was a significant increase in $\mathrm{R}_{\mathrm{a}}(p<0.05)$ with no significant alteration in $R_{d}$ or glucose clearance. There were no significant changes in serum insulin, C-peptide or glucagon levels after tyramine in the diabetic or non-diabetic subjects but there was a significant increase in mean NEFA levels in the diabetic subjects (Table $2, p<0.05$ ). NEFA levels rose comparably in four of the six non-diabetic subjects resulting in no significant difference between the NEFA responses of the two groups.

Correlations. There was a significant correlation $(r=0.64$, $p<0.02$ ) between the systolic blood pressure and glycaemic responses after oral tyramine and between the glycaemic responses and tyramine levels $(r=0.65, p<0.05)$.
Psychological stress responses. There was no group difference in baseline anxiety scores (acute anxiety, $25 \pm 2$ vs $26 \pm 2$; chronic anxiety, $35 \pm 4$ vs $34 \pm 6$; possible range, 20 80 for each). All subjects had higher scores after the task $(p<0.005)$ with the non-diabetic subjects scoring higher (delta score, $19 \pm 4$ vs $8 \pm 1, p<0.05$ ). Three subjects (two diabetic and one non-diabetic) reported not feeling stressed during the study; most reported mild to moderate irritation, frustration or anxiety; two diabetic subjects felt (and looked) severely stressed and one suffered a vasovagal syncopal attack within 5 min of completing the task. Three diabetic subjects did not complete the anxiety inventory satisfactorily.

All subjects had an increase in blood pressure and all but one an increase in heart rate (Fig.1). One diabetic subject, excluded from the results, had bradycardia with episodes of Wenckebach phenomenon (second degree heart block) as previously reported during stress [23]. The heart rate, systolic and diastolic pressor responses were not significantly different between groups (non-diabetic vs diabetic subjects, maximum heart rate increase, $16 \pm 4$ vs $11 \pm 1$ beats per min; integrated systolic pressure response, $879 \pm 235$ vs $458 \pm 66 \mathrm{~mm} \mathrm{Hg} / 60 \mathrm{~min}, p<0.1$; maximum increase, $21 \pm 5$ vs $16 \pm 5 \mathrm{~mm} \mathrm{Hg}$; integrated diastolic pressure response, $403 \pm 147$ vs $284 \pm 77$ $\mathrm{mmHg} / 60 \mathrm{~min}$ ).

NEFA levels increased significantly $(p<0.05$, Fig. 4$)$ during psychological stress in both groups (integrated responses, non-diabetic $6.81 \pm 2.26$ vs diabetic $2.35 \pm 0.86 \mathrm{mmol} /(1.60 \mathrm{~min}))$ but no significant change occurred in levels of cortisol, adrenaline or noradrenaline (Table 3). Stress did not significantly affect mean blood glucose levels in either group (Fig. 4) and no glycaemic response was seen in any individual subject. There was also no significant change in glucose turnover or pancreatic hormone levels in either group (Table 3).

Correlations. There were significant correlations between the delta anxiety score and NEFA $(r=0.71, p<0.02)$ and heart rate responses $(r=0.70, p<0.02)$ during stress. A correlation between the delta anxiety score and the adrenaline responses approached statistical significance $(r=0.59, p<0.08)$. There were also significant correla- 

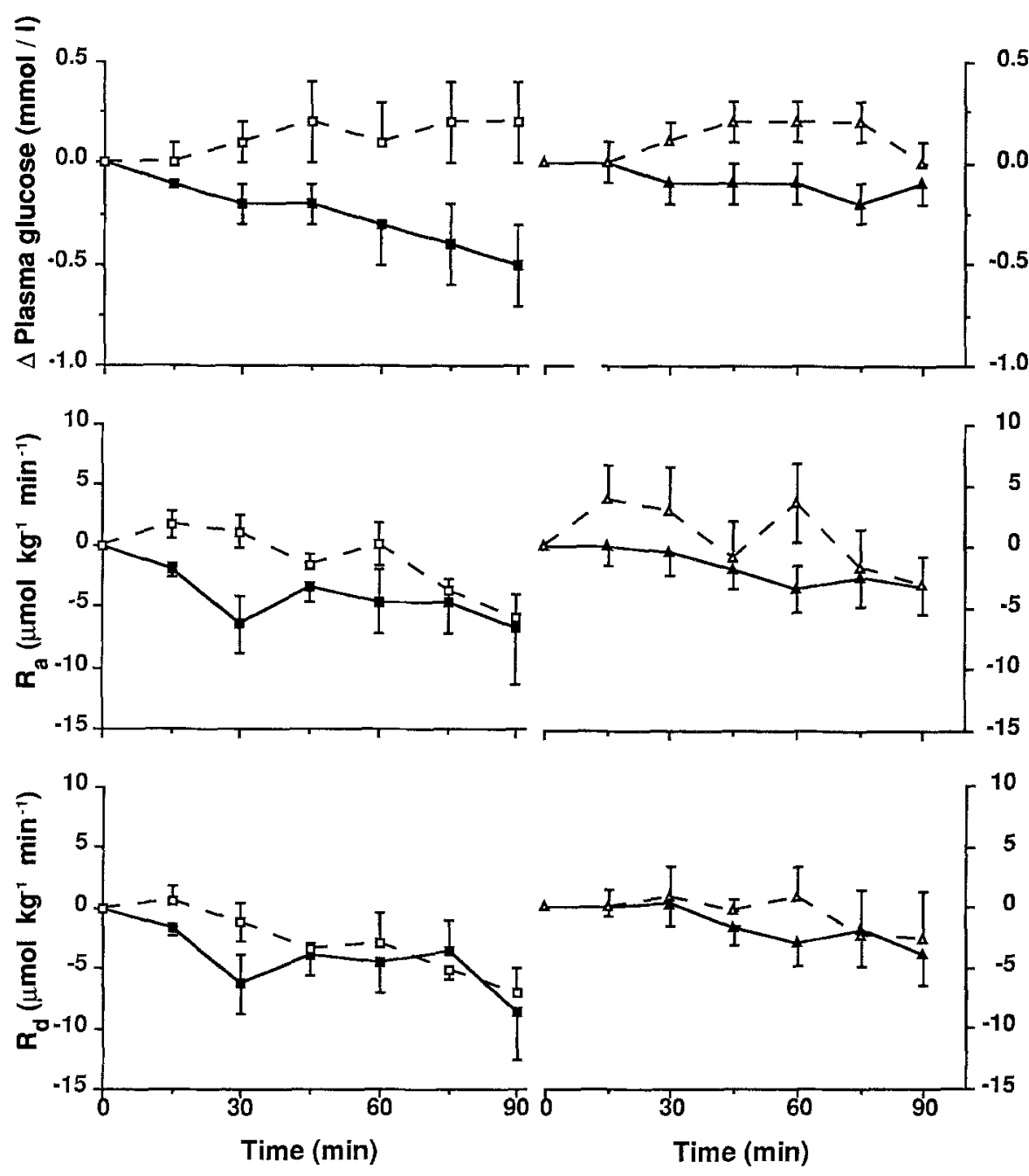

Fig. 3. Mean ( \pm SEM) incremental plasma glucose, hepatic glucose output $\left(\mathrm{R}_{\mathrm{a}}\right)$ and glucose disposal $\left(\mathrm{R}_{\mathrm{d}}\right)$ responses to oral tyramine administration at time $\mathrm{O}$ (open symbols, broken line) vs control (closed symbols) in the diabetic (left panels) and non-diabetic subjects (right panels) tions between the NEFA responses and heart rate $(r=0.73, p<0.005)$, systolic blood pressure $(r=0.63$, $p<0.02)$ and diastolic blood pressure $(r=0.66, p<0.02)$. The cortisol and diastolic pressure responses were also correlated $(r=0.64, p<0.03)$.

\section{Discussion}

The main findings of this study were that: (i) infusion of noradrenaline caused a greater hyperglycaemic and pressor response in subjects with Type 2 diabetes compared with non-diabetic subjects in the presence of similar, circulating noradrenaline levels, (ii) oral tyramine administration caused significant pressor and glycaemic responses which were not significantly different in Type 2 diabetes and non-diabetic subjects, (iii) acute psychological stress of sufficient severity to elevate pulse, blood pressure and NEFA levels failed to influence blood glucose levels in either diabetic or non-diabetic subjects.

As in other studies [24], increases in blood glucose levels in response to noradrenaline (and tyramine) were due to an initial increase in hepatic glucose production with little change in peripheral glucose uptake, although reduced glucose uptake probably had some role in prolonging hyperglycaemia. It seems likely that the hepatic glucose output responses to noradrenaline and tyramine were mediated predominantly by direct neural or local adrenergic receptor stimulation rather than by indirect humoral mechanisms. Adrenergic stimulation of hepatic glucose production is mainly driven by beta adrenergic mechanisms [25] although alpha adrenergic stimulation may also play a role [26] and both alpha ${ }_{1}$ - and beta $2_{2}$ adrenergic receptors are present in the human liver [27]. The vasoconstrictor effect of noradrenaline is mediated predominantly by alpha ${ }_{1}$-adrenergic receptors. Therefore, responses to noradrenaline demonstrated here could be mediated by alpha adrenergic mechanisms alone or in combination with beta effects. The positive correlation between the glycaemic and pressor responses to noradrenaline infusion suggests a common cause.

There was a significant initial fall in insulin and C-peptide levels during noradrenaline infusion in the diabetic subjects with similar increases in circulating glucagon levels in both subject groups which were not statistically significant. Thus, increased sensitivity of the islet Beta cells to noradrenaline could have contributed to the excessive hepatic glucose output in the diabetic subjects.

One must consider central neural activation as well as peripheral stimulation, as MHPG levels were substantially elevated in the three non-diabetic and five diabetic subjects in whom a measurement was made 30 min after 

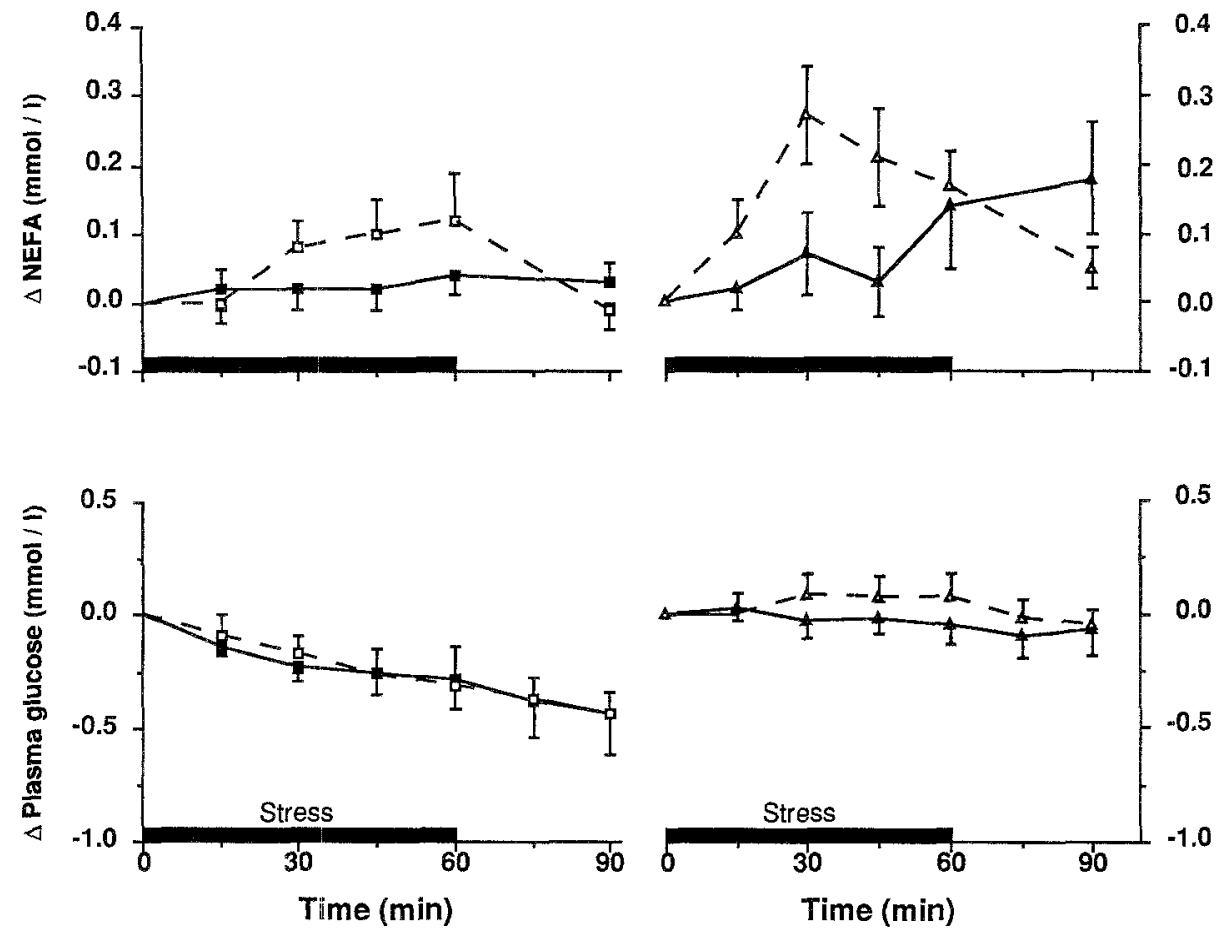

Fig. 4. Mean ( \pm SEM) incremental NEFA and plasma glucose responses during psychological stress (open symbols, broken line) vs control (closed symbols) in the diabetic (left panels) and nondiabetic subjects (right panels)

commencing noradrenaline infusion. As the MHPG rise was not accompanied by an increase in DHPG it seems possible that the MHPG rise reflects hypothalamic, or at least brain, noradrenergic activity [21].

The exaggerated pressor responses in Type 2 diabetes could conceivably be a consequence of long-term diabetes related to changes in sodium metabolism, abnormalities of the renin-angiotensin system or vessel wall thickening [28]. Increased pressor responses to noradrenaline have been recorded in hypertensive [29] and normotensive diabetic subjects [30] and attributed to these mechanisms. In these reports, subjects with Type 1 and the majority with Type 2 diabetes were grouped together. The normotensive younger, presumably Type 1 , subjects apparently had normal pressor responses [30], as found in other studies of uncomplicated Type 1 diabetes [31, 32]. However, mildly increased pressor responses have been found in subjects with retinopathy [31]. Thus, an abnormal pressor response does not necessarily occur even with long-term Type 1 diabetes and would seem to be a feature of Type 2 diabetes.
Hypersensitivity to noradrenaline due to denervation sensitivity from autonomic neuropathy seems an unlikely explanation for our results. Although this phenomenon occurs with severe symptomatic autonomic neuropathy $[32,33]$, none of the present subjects had symptoms or signs of autonomic neuropathy and the group included recently diagnosed subjects with no peripheral neuropathy and normal heart rate variation. Subclinical autonomic neuropathy may exist in some diabetic subjects [34] and two of our subjects had reduced heart rate interval variation; however, normal pressor responses to noradrenaline have been found in subjects with long-term, uncomplicated Type 1 diabetes who would almost certainly have subclinical autonomic dysfunction $[31,32]$.

Hypertension occurs commonly in Type 2 diabetes [12] and may share a common aetiology with the diabetes, possibly related to increased sympathetic activation [12]. Our results in the diabetic subjects could be explained by increased background sympathetic activity, if the activity was not normally suppressed during noradrenaline infu$\operatorname{sion}[35]$.

Table 3. Mean ( \pm SEM) values of stress and pancreatic hormones and NEFA levels during psychological stress in the diabetic $(n=8)$ and nondiabetic subjects. Data at baseline, 30 and 60 min are given

\begin{tabular}{|c|c|c|c|c|c|c|}
\hline & \multicolumn{3}{|c|}{ Type 2 (non-insulin-dependent) diabetic subjects } & \multicolumn{3}{|c|}{ Non-diabetic subjects } \\
\hline & Basal & 30 & 60 & Basal & 30 & 60 \\
\hline $\mathrm{NA}$ (radio) (nmol/l) & $1.1 \pm 0.6$ & $1.2 \pm 0.4$ & $1.0 \pm 0.5$ & $1.0 \pm 0.5$ & $1.2 \pm 0.4$ & $1.6 \pm 0.4$ \\
\hline Adrenaline $(\mathrm{nmol} / \mathrm{l})$ & $0.5 \pm 0.2$ & $0.5 \pm 0.3$ & $0.3 \pm 0.1$ & $0.7 \pm 0.5$ & $0.4 \pm 0.3$ & $0.5 \pm 0.3$ \\
\hline Cortisol $(\mathrm{nmol} / \mathrm{l})$ & $132 \pm 34$ & $181 \pm 50$ & $140 \pm 37$ & $203 \pm 30$ & $203 \pm 23$ & $159 \pm 25$ \\
\hline Insulin $(\mathrm{pmol} / \mathrm{l})$ & $90 \pm 24$ & $72 \pm 18$ & $72 \pm 18$ & $24 \pm 18$ & $24 \pm 12$ & $30 \pm 12$ \\
\hline C-peptide (nmol/1) & $0.9 \pm 0.1$ & $0.8 \pm 0.1$ & $0.8 \pm 0.1$ & $0.4 \pm 0.05$ & $0.3 \pm 0.05$ & $0.3 \pm 0.05$ \\
\hline Glucagon (ng/l) & $18 \pm 3$ & $34 \pm 12$ & $30 \pm 10$ & $59 \pm 18$ & $50 \pm 18$ & $34 \pm 9$ \\
\hline
\end{tabular}

${ }^{a} p<0.05$ compared with basal.

NA, Noradrenaline; radio, radioenzymatic measurement 
In contrast to the noradrenaline infusion, the plasma glucose elevation in response to tyramine was not significantly different between the diabetic and non-diabetic subjects but was correlated with tyramine levels. The lack of alteration in circulating insulin and glucagon levels suggests the glycaemic effects were due to direct hepatic stimulation. The diabetic subjects received less tyramine on a per $\mathrm{kg}$ basis than the non-diabetic subjects but expressing the responses in terms of $\mathrm{mg}$ tyramine $/ \mathrm{kg}$ body weight did not create any significant differences. The glycaemic response to tyramine was notably less than with noradrenaline, although the pressor responses were similar. Tyramine in vivo has weak noradrenaline releasing actions in the liver compared with the heart, probably because the liver is rich in monoamine oxidase which degrades tyramine [36].

With psychological stress, blood glucose did not increase in either subject group, despite clear cut heart rate and pressor responses and an increase in NEFA levels similar to oral tyramine. As a group, the diabetic subjects had significantly lower anxiety scores (which correlated with NEFA, heart rate and adrenaline responses). It is possible that real life stresses, particularly if prolonged, would have a greater metabolic impact, including cortisol and growth hormone responses, on subjects with Type 2 diabetes, or might reduce compliance with therapy. Alternatively, chronic psychological stress causing sustained elevations in fatty acids might eventually inhibit glucose metabolism [37], reduce insulin sensitivity [38] and lead to glucose intolerance [39].

In conclusion, a group of subjects with Type 2 diabetes with some heterogeneity of duration, body mass index and blood pressure have an exaggerated blood glucose response to pharmacological elevations of circulating noradrenaline. The responses to noradrenaline in comparison to tyramine and psychological stress suggest the possibility of increased activity of the sympathetic nervous system or increased sensitivity of catecholamine receptor mechanisms in Type 2 diabetes. It would be interesting to determine whether these phenomena are also associated with impaired insulin sensitivity without hyperglycaemia in the "syndrome X" constellation of glucose intolerance, insulin resistance, hypertension and dyslipoproteinaemia $[13,40]$. Measures aimed at reducing sympathetic activation could have therapeutic value in Type 2 diabetes.

Acknowledgements. The excellent assistance of Ms M. O'Brien, Ms J.Sowden, Dr. A. Jenkins, Ms D. Barnett, Mr. P. Clark and Ms S. Mitchell is gratefully acknowledged. This work was supported by a Centre Grant to the Garvan Institute from the National Health and Medical Research Council (Australia). Dr. Bruce was supported by a CSL-Novo Scholarship.

\section{References}

1. Shimazu $T$ (1981) Central nervous system regulation of liver and adipose tissue metabolism. Diabetologia 20:343-356

2. Lautt WW (1983) Afferent and efferent neural roles in liver function. Prog Neurobiol 21:323-348

3. Smythe GA, Grunstein HS, Bradshaw JE, Nicholson MV, Compton PJ (1984) Relationships between brain noradrenergic activity and blood glucose. Nature 308: 65-67
4. Nobin A, Galck B, Ingemansson S, Jarhult J, Rosengren E (1977) Organisation and function of the sympathetic innervation of human liver. Acta Physiol Scand 452: 103-106

5. Robertson RP, Halter JB, Porte D Jr (1976) A role for alphaadrenergic receptors in abnormal insulin secretion in diabetes mellitus. J Clin Invest 57: 791-796

6. Broadstone VL, Pfeiffer MA, Bajaj V, Stagner JI, Samols E (1987) Alpha-adrenergic blockade improves glucose-potentiated insulin secretion in non-insulin-dependent diabetes mellitus. Diabetes 36: 932-937

7. Kashiwagi A, Harano Y, Suzuki M et al. (1986) New alpha $2^{-}$ adrenergic blocker (DG-5128) improves insulin secretion and in vivo glucose disposal in NIDDM Matients. Diabetes 35:1085-1089

8. Surwit RS, Feinglos MN (1988) Stress and autonomic nervous system in type II diabetes: a hypothesis. Diabetes Care 11: 83-85

9. Surwit RS, Feinglos MN (1983) The effects of relaxation on glucose tolerance in non-insulin-dependent diabetes. Diabetes Care 6:176-179

10. Feinglos MN, Hastedt P, Surwit RS (1987) Effects of relaxation therapy on patients with type I diabetes mellitus. Diabetes Care 10: $72-75$

11. Kemmer FW, Bisping R, Steingruber HJ (1986) Psychological stress and metabolic control in patients with type I diabetes mellitus. N Engl J Med 314: 1078-1084

12. Drury PL (1983) Diabetes and arterial hypertension. Diabetologia $24: 1-9$

13. Zavaroni I, Bonora E, Pagliara M et al. (1989) Risk factors for coronary artery disease in healthy persons with hyperinsulinemia and normal glucose tolerance. N Engl J Med 320: 702-706

14. Chipps DR, Kraegen EW, Zelenka GS, McNamara ME, Chisholm DJ (1981) Cardiac beat to beat variation: age related changes in the normal population and abnormalities in diabetics. Aust NZ J Med 11: 614-620

15. McGuire EAH, Helderman JH, Tobin JD, Andres R, Berman M (1976) Effects of arterial versus venous sampling on analysis of glucose kinetics in man. J Appl Physiol 41:565-573

16. Jenkins AB, Furler SM, Chisholm DJ, Kraegen EW (1986) Regulation of hepatic glucose output during exercise by circulating glucose and insulin in humans. Am J Physiol 250: R411-R417

17. Carroll D, Hewitt JK, Last KA, Turner JR, Sims J (1985) A twin study of cardiac reactivity and its relationship to parental blood pressure. Physiol Behav 34: 103-106

18. Spielberger CD, Gorsuch RL, Lushene R, Vagg PR, Jacobs GA (1983) Manual for the state-trait anxiety inventory (self-evaluation questionnaire). Consulting Psychologists Press, Palo Alto

19. Bruce DG, Storlien LH, Furler SM, Chisholm DJ (1987) Cephalic phase metabolic responses in normal weight adults. Metabolism 36: 721-725

20. Smythe GA, Duncan MW, Bradshaw JE, Cai WY (1982) Serotoninergic control of growth hormone secretion: hypothalamic dopamine, norepinephrine, and serotonin levels and metabolism in three hyposomatotropic rat models and in normal rats. Endocrinology 110: 376-383

21. Grunstein HS, Gleeson RM, Smythe GA (1986) Relationship between hypothalamic noradrenergic neuronal activity and serum 3-methoxy-4-hydroxyphenylethylene glycol in the rat. Life Sci 39: 207-213

22. Hother-Nielsen O, Beck-Nielsen H (1990) On the determination of basal glucose production rate in patients with type 2 (noninsulin-dependent) diabetes mellitus using primed-continuous $3-{ }^{3} \mathrm{H}$ glucose infusion. Diabetologia 33: 603-610

23. Carruthers M, Taggart P (1973) Vagotonicity of violence: biochemical and cardiac responses to violent films and television programmes. Br Med J 3: 384-389

24. Sacca L, Morrone G, Cicala M, Corso G, Ungaro B (1980) Influence of epinephrine, norepinephrine and isoproterenol on glucose homeostasis in normal man. J Clin Endocrinol Metab 50: $680-684$

25. Rizza RA, Cryer PE, Haymond MW, Gerich JE (1980) Adrenergic mechanisms for the effects of epinephrine on glucose production and clearance in man. J Clin Invest 65: 682-689 
26. Rosen SG, Clutter WE, Shah SH, Miller JP, Bier DM, Cryer PE (1983) Direct alpha-adrenergic stimulation of hepatic glucose production in human subjects. Am J Physiol 245: E616-E626

27. Kawai Y, Powell A, Arinze IJ (1986) Adrenergic receptors in human liver plasma membranes: predominance of beta $2^{-}$and alpha ${ }_{1}$-receptor subtypes. J Clin Endocrinol Metab 62: 827-832

28. De Chatel R, Weidmann P, Flammer J et al. (1977) Sodium, renin, aldosterone, catecholamines, and blood pressure in diabetes mellitus. Kidney Int 12: 412-421

29. Weidmann P, Beretta-Piccoli C, Keusch G et al. (1979) Sodiumvolume factor, cardiovascular reactivity and hypotensive mechanism of diuretic therapy in mild hypertension associated with diabetes mellitus. Am J Med 67: 779-784

30. Beretta-Piccoli C, Weidmann P (1981) Exaggerated pressor responsiveness to norepinephrine in nonazotemic diabetes mellitus. Am J Med 71: 829-835

31. Christlieb AR, Janka H, Kraus B et al. (1976) Vascular reactivity to angiotensin II and to norepinephrine in diabetic subjects. Diabetes 25: 268-274

32. Scobie IN, Rogers PT, Brown PM, Godfrey H, Sönksen PH (1987) Supersensitivity to both tyramine and noradrenaline in diabetic autonomic neuropathy. J Neurol Neurosurg Psych 50: 275-278

33. Hilsted J, Richter E, Madsbad S et al. (1987) Metabolic and cardiovascular responses to epinephrine in diabetic autonomic neuropathy. N Engl J Med 317: 421-426

34. Pfeiffer MA, Weinberg CR, Cook DL et al. (1984) Autonomic neural dysfunction in recently diagnosed diabetic subjects. Diabetes Care 7: 447-453
35. Izzo JL Jr (1982) Alpha-adrenergic suppression of the sympathetic nervous system and altered norepinephrine kinetic calculations during norepinephrine infusions in man. Clin Res 30: $272 \mathrm{~A}$ (Abstract)

36. Garceau D, Yamaguchi N (1982) Pharmacological evidence for the existence of a neuronal amine uptake mechanism in the dog liver in vivo. Can J Physiol Pharmacol 60: 755-762

37. Randle PJ, Garland PB, Hales CN, Newsholme EA (1963) The glucose fatty-acid cycle: its role in insulin sensitivity and the metabolic disturbances of diabetes mellitus. Lancet I: 785-789

38. Ferrannini E, Barrett EJ, Bevilacqua S, DeFronzo RA (1983) Effect of fatty acids on glucose production and utilization in man. J Clin Invest 72: 1737-1747

39. Rouselle J, Buckert A, Pahud P, Jequier E, Felber JP (1982) Relationship between glucose oxidation and glucose tolerance in man. Metabolism 31: 866-870

40. Reaven GM (1988) Role of insulin resistance in human disease. Diabetes 37: 1595-1607

Received: 16 September 1991

and in revised form: 29 April 1992

\section{Dr. D.J.Chisholm}

Garvan Institute of Medical Research

St. Vincent's Hospital

Darlinghurst NSW 2010

Australia 